\title{
PERAN HUMAN CAPITAL PENGRAJIN SEPATU SEBAGAI DAYA SAING DALAM RANGKA MENINGKATKAN TURIS DI JAWA BARAT (KAJIAN PADA SENTRA CIBADUYUT JAWA BARAT)
}

\author{
Joeliaty \\ joeliaty@yahoo.co.id \\ FAKULTAS EKONOMI DAN BISNIS UNIVERSITAS PADJADJARAN
}

\begin{abstract}
Abstrak
Industri kreatif adalah salah satu industri yang memiliki daya tarik wisata mancanegara (wisman) untuk berkunjung ke Indonesia. Kawasan sentra industri sepatu Cibaduyut merupakan salah satu sentra kawasan industri kreatif yang berada di daerah kota Bandung Jawa Barat. Sentra Cibaduyut menawarkan produk handmade yang punya keunikan, originalitas dan awet, yang sangat di sukai di pasaran international. Ini cukup potensial menarik wisata mancanegara untuk dapat mengunjungi sentra Cibaduyut, baik untuk cindramata ataupun menjadi komonditi ekspor. Oleh karena itu dalam rangka memenuhi kebutuhan wisman tersebut dibutuhkan adanya keterampilan khusus dari para pengrajin sepatu . Saat ini tantangan yang terbesar adalah belum adanya regenerasi dalam bidang keterampilan pembuatan sepatu sebagai daya saing. Pengrajin yang memiliki keterampilan cenderung untuk beralih profesi. Selain itu tantangan dari segi pemasaran ditandai dengan membanjirnya produk sepatu impor dengan harga lebih murah, tetapi kualitas kalah dengan hasil lokal produk hand made Cibaduyut. Untuk memperkuat reputasi dan citra tersebut, maka dibutuhkan, sumber daya manusia (human capital ) yang unggul , memiliki kompetensi dalam menghadapi tantangan yang ada. Dalam penelitian ini akan diungkap seberapa jauh peran dari human capital pengrajin sepatu sentra sepatu Cibaduyut sebagai daya saing yang akan menarik wisman di Jawa Barat. Sedangkan metode penelitian yang digunakan adalah metode deskriptif untuk mengungkap tentang peran human capital apasaja yang dapat meningkatkan wisman. Yang didukung dengan data primer melalui questioner yang akan dibagikan pada semua pengrajin sepatu sebagai responden yang telah ditentukan berdasarkan random sampling. Hasil penelitian mengungkap bahwa peran human capital pengrajin sepatu adalah harus "sebagai agen perubahan", atau sebagai pengrajin sepatu dituntut untuk semakin mampu mengidenfifikasi perubahan-perubahan lingkungannya dan mempu merespon perubahan tersebut.
\end{abstract}

Kata kunci : Human Capital, Daya Saing, Wisman 


\section{Pendahuluan}

\subsection{Latar Belakang Penelitian}

Sektor pariwisata di Indonesia telah memberikan sumbangannya sebagai penyelamat di saat krisis terjadi sekaligus memberikan dampak ganda (multiplier effect) yang cukup besar pada pertumbuhan sektor-sektor lain. Perkembangan inipun dapat menghidupkan banyak usaha kecil sektor informal yang terkait dengan kegiatan wisata, antara lain asongan, warung jasa pemandu wisata dan sebagainya (Damanik dkk, 2005:36 ; Yan Megawati 2013 :77).

Berdasarkan data statistik rengking devisa pariwisata mengalami fluktuatif ,pada awalnya tahun 2009 berada pada rengking empat pata tahun 2010,2011,2012 berada pada rangking lima dan pada tahun 2013 kembali lagi pada rangking ke empat.Hal ini menandakan potensi wisata sangat menjajikan dalam mendongkrak devisa negara. Sedangkan berdasarkan Kementrian Pariwosata dan BPS 2015 , jumlah wisman dari tahun 2009 sampai tahun 2013 selalu mengalami kenaikan, tetapi tingkat pertumbuhannya fluktuatif. Dalam rangka mendukung strategi Pemerintah menargetkan 20 juta wisman tahun 2019 , kota Bandung merupakan salah satu kota tujuan pariwisata baik wisatawan lokal maupun wisatawan mancanegara. Berdasarkan data dari BPS ,jumlah wisman yang berkunjung ke kota Bandung dari tahun 2009 sampai dengan tahun 2013 sebagai berikut : tahun 2009 berjumlah 168.712 wisman, dalam penelitian ini diasumsikan sebagai tahun dasar. Tahun 2010 adalah 180.603 wisman dan mengalami kenaikan sebesar $7 \%$ di bandingkan tahun tahun 2009. Tahun 2011 adalah 194.064 wisman dan mengalami kenaikan sebesar 7\% di bandingkan tahun tahun 2010. Tahun 2012 adalah 158.848 wisman dan mengalami penurunan sebesar 22\% di bandingkan tahun 2011. Dan tahun 2013 adalah 170.982 wisman dan mengalami kenaikan sebesar 8\% di bandingkan tahun tahun 2012.

Pada saat ini industri kreatif, menjadi wajah baru Indonesia yang potensial. Industri kreatif menjadi sumber pertumbuhan ekonomi negara berkembang (Tantie, koestantia, dkk ; 2014). Salah satunya sebagai daya tarik wisman untuk berkunjung ke Indonesia. Kawasan sentra industri sepatu Cibaduyut merupakan sentra kawasan industri dari lima kawasan industri yang ditetapkan pemerintah Kota Bandung, yakni Cigondewah sentra industri kain, Cihampelas sentra industry jins, Suci sentra industri kaos dan Binongjati sentra industri rajutan.

Dalam penelitian ini melakukan kajian pada sentra Cibaduyut Jawa Barat yang termasuk : Pariwisata untuk usaha dagang (business tourism). Kawasan Cibaduyut, Kec. Bojongloa Kidul merupakan kawasan industi sepatu kulit, tas kulit, jaket kulit, dan sabuk kulit, yang sudah melegenda di Indonesia, keberadaan kawasaan ini sudah ada sejak jaman penjajahan Belanda sampai saat ini. Kawasan Cibaduyut berada 2 KM dari pusat Kota Bandung. Dari data BPS Kota Bandung pada tahun 2012 jumlah pengrajin di Cibaduyut yang termasuk kualifikasi sedang sebanyak 398 pengrajin, sedangkan kualifikasi kecil 499 pengrajin. Pada tahun 2013 jumlah pengrajin di Cibaduyut yang termasuk kualifikasi besar 1 pengrajin, sedang 4 dan kualifikasi kecil 1.795 pengrajin. Jumlah wisman yang datang ke sentra Cibaduyut berdasarkan wawancara peneliti dengan Bapak Alex [pada tanggal 28 Mei 2015] Kepala UPT Balai Pengembangan Perindustrian (BPP) Instalisasi Pengembangan Industri Kecil Menengah (IKM) Persepatuan Cibaduyut "Belum ada data pasti jumlah wisman yang berkunjung ke sentra Cibaduyut setiap tahun, tapi menurut pengamatan sekitar 200 sampai 500 wisman yang berkunjung ke sini, ratarata wisman berasal dari Malaysia, Singapura, Brunai, Belanda, negara Eropa Lain dan Amerika". Selain itu pula peneliti melakukan wawancara dengan pengrajin sepatu Desy [pada 
tanggal 26 Mei 2015] yang merupakan pemilik merk sepatu Onnassis, menyatakan bahwa “ Wisman yang datang ke sini rata-rata tidak menentu, dalam sebulan 1 sampai 5 wisman, biasanya datang dari eropa seperti Belanda, Jerman, selain itu ada yang dari Amerika, mereka biasanya membuat memesan lebih dari satu pasang dan untuk di jual lagi di Negaranya. Pembuatan sepatu disini bisa custom sesuai dengan permintaan pelanggan dan menyediakan size/ukuran untuk sepatu yang besar".

Sentra Cibaduyut menawarkan produk handmadeyang punya keunikan, originalitas dan awet, yang sangat di sukai di pasaran international. Ini cukup potensial menarik wisman untuk dapat mengunjungi sentra Cibaduyut, baik untuk cindramata ataupun menjadi komonditi ekspor. Beberapa tantangan yang di hadapi sentra Cibaduyut agar memiliki daya saing dan dapat meningkatkan kunjungan wisatawan belanja ke sentra industri sepatu Cibaduyut adalah sebagai berikut : (1). Regenerasi keterampilan menjadi salah satu tantangan bagi sentra sepatu cibaduyut. Persoalan ini harus dihadapi bersamaan dengan sulitnya bertahan di tengah bersaing produk pasaran. Berdasarkan wawancara [pada tanggal 28 Mei 2015] dengan Bapak Alex Kepala UPT BPP IKM Persepatuan Cibaduyut Berdasarkan dan dengan E. Aries Haryadi pemilik merk sepatu Nakerschu, mengatakan bahwa ,beberapa tahun silam, mencari pekerja tambahan bukan hal yang sulit. Sejumlah tetangganya memiliki keterampilan untuk membuat alas kaki. Namun saat ini, jumlah terus berkurang. Pengrajin yang memiliki keterampilan cenderung untuk beralih profesi. Atau kalaupun masih bergelut di produksi alas kaki, pengrajin akan pindah ke industri berskala pabrik. Ditengarai, ini berkaitan dengan pendapatan yang lebih menjanjikan. Saat bekerja di pabrik, pendapatan cenderung lebih terjamin. Penggunaan teknologi membuat keterampilan utama yang dibutuhkan bukan kemampuan membuat sepatu, melainkan kemampuan menggunakan mesin. Sementara saat bekerja di industri rumah tangga, bisa jadi pendapatan yang diterima perajin tidak menentu. (2).Membanjirnya produk impor, selain dari sisi produksi, tantangan juga datang dari sisi pemasaran yang dibanjiri oleh produk impor. Saat ini, produk alas kaki yang dipajang di ratusan gerai sepanjang jalan Cibaduyut Raya tidak hanya buatan sentra lokal, tapi juga produk luar, baik dari sentra industry alas kaki lain di Indonesia, maupun produk serupa impor dari Tiongkok. [PR Online 7 Maret 2012, diakses 30 Mei 2015].Ini diperkuat dari hasil wawancara keberapa pengrajin salah satunya Desy [pada tanggal 26 Mei 2015] yang merupakan pemilik merk sepatu Onnassis, menyatakan bahwa" Produk sepatu Cibaduyut dalam persaingannya sudah mulai kalah bersaing dikarenakan membanjiri produk impor yang harganya lebih murah tetapi kualitasnya kalah dengan produk handmade Cibaduyut".

Hasil penelitian Ghea Utariani S dan Reza Anshari N (2013) mendapat temuan bahwa hambatan pengerajin sentra sepatu Cibaduyut tidak memiliki kepercayaan diri untuk merk asli pengrajin, dikarenakan citra merek lokal masih kurang mendapatkan kepercayaan pelanggan khususnya seperti desain, dan kualitas. Untuk memperkuat reputasi dan citra tersebut, maka dibutuhkan, sumber daya manusia yang unggul (competitive advantage resource base value),memiliki kompetensi dalam menghadapi tantangan yang ada. faktor yang paling berkontribusi dalam penciptaan dan pemeliharaan keunggulan organisasi adalah sumber daya manusia/human capital (Berger ; 2008 dalam Joeliaty ; 2012 :2).

Selain itu diperkuat dari hasil penelitian Joeliaty (2014) mendapatkan temuan bahwa kompentensi pengrajin sepatu Cibaduyut dalam menghadapi Masyarakat Ekonomi ASEAN (MEA)adalah pengetahuan yaitu sebesar 80,2\% dituntut lebih agar dapat minimal bertahan dalam persaingan. Pengetahuan pengrajin modal penentu human capital dan sumberdaya tidak berwujud perusahaan dalam mengelola keunggulan bersaing (Djurica, Maca et al 2014 : 555) 
Beberapa penelitian tentang pengrajin sepatu dalam meningkatkan keunggulan daya saing di sentra industri Cibaduyut. Seputar branding Cibaduyut seperti yang dilakukan oleh (Ghea Utariani S dan Reza Anshari N : 2013), kebijakan pemerintah terkait dengan pola pesebaran tujuan wisata (Tantie Kostantia dkk ; 2014 :1141) dan pengembangan daerah wisata (Yulia Widarti : 2015 : 551).Namun masih jarang penelitian yang dilakukan terkait dengan peran human capital dalam upaya meningkatkan keunggulan bersaing (competitive advantage resource base value) pengrajin sentra industri Cibaduyut. Lebih dalam lagi penelitian mengenai human capital yang dibutuhkan dalam meningkatkan keunggulan bersaing, upaya menarik wisman berkunjung ke sentra industri Cibaduyut.

\subsection{Rumusan Masalah}

Berdasarkan latar belakang diatas , maka dapat dirumuskan masalah penelitian ini adalah, bagaimana peran dari human capital pengrajin sepatu di sentra sepatu Cibaduyut Jawa Barat dapat menjadi daya saing dalam rangka meningkatkan jumlah wisman Jawa Barat.

\subsection{Tujuan Penelitian}

Tujuan dari penelitian ini adalah memberikan gambaran peran human capital pengrajin sepatu sebagai daya saing pada sentra sepatu Cibaduyut Jawa Barat, dalam rangka meningkatkan kunjungan wisman.

\subsection{Metode Penelitian}

Penelitian ini merupakan penelitian yang akan melihat bagaimana gambaran kondisi peran human capital sebagai daya saing pengrajin sepatu sentra industri Cibaduyut yang akan memberikan kontribusi pada peningkatan jumlah wisman ke Jawa Barat . Dan mengetahui kondisi keadaan pengrajin sepatu sentra Cibaduyut apakah masih dapat bersaing dengan kondisi saat ini.

Dalam penelitian ini metode yang digunakan adalah metode survey explanotary dikarenakan untuk mengetahui gambaran umum variable, ditindaklanjuti dengan metode deskritif (Istijanto, 2006 :20) dan verivikatif dengan menggunakan analisis faktor yang dibantu dengan software SPSS 22.for windows. Hal ini dilakukan untuk mengetahui pengelompokan analisis pemetaan dimensi-dimensi yang membentuk peran human capital pengrajin . .Dalam penelitian ini juga dijaring dengan jenis data yang digunakan adalah data primer yang diperoleh melalui questioner terhadap 81 orang pengrajin sepatu dan data sekunder .Permasalahan yang kompleks tidak dapat diisolasikan ke dalam variabel, tetapi perlu memandangnya sebagai bagian dari kesatuan atau keutuhan. Hal inilah yang menyebabkan peneliti menggunakan metode kualitatif dan kuantitatif, mengingat pada penelitian ini peneliti akan berhubungan dengan sebuah organisasi, dan tentu saja berurusan dengan individu dan masyarakat.Adapun teknik pengumpulan data yang dilakukan melalui observasi, wawancara dan studi pustaka.

\section{II.Tinjauan Pustaka}

Target 20 juta wisman pada tahun 2019 ke Indonesia, merupakan tantangan bukan hanya pemerintahaan saat ini saja. Melainkan ini menjadi tantangan bersama para stackholder, dengan meningkatkan kunjungan wisman ke Indonesia. Tentunya akan mempunyai implikasi yang 
signifikan terhadapa devisa negara dan tentunya multipier effect, bagi warga sekitar daerah wisata. Sentra Industi Cibaduyut Jawa Barat merupakan salah satu tujuan wisata belanja, dalam penelitian ini peneliti memetakan masalah yang terkait dengan peran human capital khususnya kekurangan regenerasi baru pengrajin sepatu. Ada pengaruh positif human capital terhadap keunggulan bersaing Emily Auw (2009:30) hal ini di perkuat dengan hasil penelitian oleh (Variyam \& Kraybill, 1993;Emily Auw, 2009:30) . Perusahaan yang memiliki human capital tinggi cenderung lebih baik dalam meningkatkan kemampuan perusahaan.

Dengan diberlakukannya MEA para pengrajin sepatu di Cibaduyut diharapkan dapat bersiap dan berani bersaing dengan produk dari negara lain. Salah satu akibat dari kerjasama ekonomi yang lebih terbuka bagi kegiatan industry adalah masuknya produk luar ke dalam pasar lokal. Saat ini produk-produk Cina sudah memasuki pasar Indonesia yang menimbulkan persaingan dengan produk lokal. Dengan sistem produksi massal Cina menggunakan alat produksi yang canggih sehingga memilki kapasitas produksi yang besar dan mampu menekan harga produk lebih murah (Sebayang, 2012).

Tantangan tersebut juga dialami oleh industri sepatu Cibaduyut. Sebagai salah satu sentra utama industri sepatu di Indonesia, Cibaduyut merupakan salah satu elemen penting yang dapat memicu pertumbuhan lokal. Produk sepatu Cibaduyut harus mampu bersaing dengan produk-produk luar dalam persaingan global.Para pengrajin sepatu di Cibaduyut perlu dibenahi dan dibekali keterampilan hingga mereka mampu menghadapi pasar bebas MEA 2015, salah satunya melalui pengembangan sumber daya manusia dalam hal ini human capital sangat berperan, sehingga para pengrajin sepatu dapat meningkatkan pengetahuan yang mereka miliki agar produk yang mereka hasilkan bisa memiliki daya saing baik secara kualitas, desain, kemasan dan harga yang kompetitif, yang akan menarik para wisman.

Human capital sebagai intangible capital yaitu Sumber Daya Manusia (SDM) yang memegang peran strategis dalam upaya daya mendongkrak daya saing perusahaan, berikut peneliti sarikan beberapa definisi human capital.Human capital adalah sebuah konsep yang terdiri dari pendidikan, pengalaman, dan keterampilan pada titik waktu tertentu (Boxall \& Steeneveld, 1999) dalam Emily Auw (26 : 2009). Menurut Castanias \& Helfat (1991) dalam Emily Auw (26 : 2009), pengertian human capital adalah variasi dalam kemampuan karyawan perketerampilan akan menentukan hasil dari keunggulan kompetitif. Sebuah pandangan tersebut didukung oleh Peteraf \& Barney (2003), perusahaan yang memiliki karyawan dengan kemahiran lebih khusus-industri perusahaan akan memiliki keuntungan. Sedangkan human capital menurut Baron dan Amstrong (2007 :6) adalah pengetahuan, keterampilan, kemampuan dan kapasitas untuk mengembangkan dan berinovasi dimiliki oleh orang-orang dalam suatu organisasi dan dibutuhkan, sumber daya manusia yang unggul (competitive advantage resource base value).Berkaitan dengan human capital, Ulrich (1997) dalam Joeliaty (2014 : 6) mengatakan, ada empat peran human capital guna membangun organisasi yang kuat, yaitu: (1) management of strategy human resources (berperan sebagai mitra dalam penentuan strategi perusahaan), (2) management of transformation and change (menjadi agen perubahan dan transformasi organisasi), (3) management of firm infrastructure (ahli dalam proses administrasi), dan (4) management of employee contribution (bermain pada wilayah kontribusi dan menjadi pemenang). Masing-masing peran mempunyai spesifikasi tersendiri. Melalui berbagai peran tersebut akan meningkatkan daya saing suatu organisasi.

Peran human capital merupakan faktor utama sebagai daya saing bagi para pengrajin sepatu Cibaduyut dalam rangka meningkatkan wisata mancanegara. Human capital merupakan penggerak kearah kesuksesan sehingga memiliki daya saing, karena melalui peran human 
capital maka para pengrajin sepatu akan memiliki kompetensi yang sesuai bidangnya dengan menghasilkan produk yang memiliki kualitas yang baik dan diminati oleh konsumen dalam dan luar negeri.Dengan adanya peran dari human capital tersebut diharapkan dapat mendorong terciptanya inovasi baik secara kelompok atau individu guna mendukung pertumbuhan usaha dan meningkatkan daya saing yang akan membantu core business activities berjalan lebih efektif sehingga memberikan nilai utilitas optimal bagi pengrajin, konsumen, dan stakeholder.

\section{Hasil Dan Pembahasan}

\subsection{Profil Responden}

Responden dalam penelitian ini adalah pengrajin sepatu di Cibaduyut yang berjumlah 81 orang. Adapun karakteristik responden yang dapat disajikan dalam penelitian ini meliputi beberapa aspek, yaitu: jenis kelamin, usia, pendidikan formal terakhir, masa kerja, serta status perkawinan responden. Untuk lebih jelasnya mengenai aspek-aspek karakteristik responden tesebut, dapat dilihat dalam penjelasan dibawa ini :

Pengrajin sepatu dari segi usia, mayoritas termasuk kedalam usia produktif yakni berkisar antara 31-40 tahun sebanyak 39 orang (48\%). Artinya dalam usia tersebut merupakan masa-masanya bagi para pengrajin menyenangi bidang-bidang pekerjaan yang cukup menantang dalam mengaplikasikan idealismenya.Namun demikian, yang harus diwaspadai adalah usia yang sudah tidak lagi muda, dimana terdapat 11 orang $(20,88 \%)$ berada pada kelompok umur diatas 50 tahun yang relatif sudah tidak produktif lagi untuk pekerjaan teknis. Selain itu, perlu juga diperhatikan kelompok usia 41 - 50, dimana dalam kurun waktu 5 sampai dengan 10 tahun kedepan akan memasuki usia tidak produktif. Kondisi ini tentunya menuntut untuk dapat melakukan pengelolaan kesehatan dengan baik untuk mengantisipasi penurunan produktivitas dimasa yang akan datang.

Karakteristik dari segi pendidikan, menggambarkan tingkat pendidikan para pengrajin sepatu diadalah tingkat pendidikan SMA sebanyak 31orang (38\%),kemudian urutan kedua dengan tingkat pendidikan SD sebanyak 19 orang (23\%), selanjutnya SMP sebanyak16 orang (20\%), sedangkan responden yang bependidikan Sarjana sebanyak 11 orang (14\%) dan Diploma (D1/D3/D4)berjumlah sebanyak 4 orang (5\%). Dengan demikian dapat disimpulkan bahwa sebagian besar tingkat pendidikan para pengrajin sepatu di Cibaduyut adalah SMA, sudah memenuhi persyaratan sesuai dengan ketentuan yang berlaku. Namun, agar dapat meningkatkan kredibiltas dan kemampuan dalam pengetahuan dan pelayanan yang profesional dan berkualitas, para pengrajin masih dapat meningkatkan tingkat pendidikannya untuk dapat menuntut ilmu dan pengetahuan lebih giat baik formal maupun informal.

Dri segi masa kerja, rata-rata masa kerja para pengrajin sepatu di Cibaduyut, antara 6 - 10 tahun sebanyak 29 orang (36\%). Artinya mereka memiliki kemampuan dan pengalaman yang cukup, sehingga mereka layak diberikan kesempatan lebih untuk dapat meningkatkan kariernya.Namun bukan tidak mungkin, dengan masa kerja yang terlalu lama tersebut timbul rasa jenuh pada diri pengrajin, sehingga dapat menyebabkan turunnya kinerja.

Sedangkan karakteristik pengrajin dari segi status perkawinan, sebagian besar para pengrajin sepatu di Cibaduyut berstatus menikah yaitu sebanyak 69 orang (85\%). Hal ini juga perlu mendapat perhatian para pengrajin sepatu di Cibaduyut,karena beban kebutuhan hidup 
mereka tentunya akan lebih besar dibandingkan dengan pengrajin yang belum menikah,sehinga perlu dorongan dan pertimbangan dalam hal kesejahteraan finansialnya.

\subsection{Gambaran Peran Human Capital Pengrajin Sepatu Di Sentra Sepatu Cibaduyut Jawa Barat}

Berdasarkan pendapat Dave Ulrich ,(1997) ,bahwa peran Human Capital, terdiri dari empat dimensi yaitu Mitra Strategik, Ahli Administratif, Infrastruktur dan Agen Perubahan. Dari Dimensi mitra strategik terdiri empat indikator yaitu arsitektur organisasional, audit organisasional, identifikasi metode \& renovasi arsitektur organisasional, inisiatif dalam menyusun prioritas. Dimensi Ahli Admistraktif terdiri dari empat indikator yaitu staffing, rewarding, training, dan penilaian. Dimensi infrastruktur terdiri dari lima indikator proses operasional, komitmen, kontribusi, loyalitas, dan kemampuan sdm / kinerja. Terakhir dimensi agen perubahan terdiri dari empat indikator yaitu menangkap perubahan, mengkapitalisasi perubahan, inisiatif perubahan dan strategi sdm masa depan. Untuk lebih jelasnya terlihat di Tabel 3.1.1tentang peran human capital pengrajin sebagai mitra srtategis, sebagai berikut

Tabel 3.1.

\section{Peran Human Capital Pengrajin Sepatu Sebagai Mitra Strategis}

\begin{tabular}{|c|c|c|c|c|c|c|c|}
\hline Dimensi & No. & SS (5) & $S(4)$ & RR (3) & TS (2) & STS (1) & Total \\
\hline \multirow{8}{*}{$\begin{array}{c}\text { Arsitektur } \\
\text { Organisasional }\end{array}$} & \multirow{2}{*}{1.} & 26 & 48 & 6 & 1 & 0 & 81 \\
\hline & & $32,1 \%$ & $59,3 \%$ & $7,4 \%$ & $1,2 \%$ & 0 & $100 \%$ \\
\hline & \multirow{2}{*}{2.} & 24 & 45 & 9 & 3 & 0 & 81 \\
\hline & & $29,6 \%$ & $55,5 \%$ & $11,1 \%$ & $3,7 \%$ & 0 & $100 \%$ \\
\hline & \multirow{2}{*}{3.} & 17 & 49 & 13 & 2 & 0 & 81 \\
\hline & & $21 \%$ & $60,5 \%$ & $16,0 \%$ & $2,5 \%$ & 0 & $100 \%$ \\
\hline & \multirow{2}{*}{4.} & 26 & 39 & 10 & 5 & 1 & 81 \\
\hline & & $32,1 \%$ & $48,1 \%$ & $12,3 \%$ & $6,2 \%$ & $1,2 \%$ & $100 \%$ \\
\hline \multirow{4}{*}{$\begin{array}{c}\text { Audit } \\
\text { Organsasional }\end{array}$} & \multirow{2}{*}{5.} & 22 & 40 & 7 & 7 & 5 & 81 \\
\hline & & $27,2 \%$ & $49,4 \%$ & $8,6 \%$ & $8,6 \%$ & $6,2 \%$ & $100 \%$ \\
\hline & \multirow{2}{*}{6.} & 13 & 43 & 13 & 8 & 4 & 81 \\
\hline & & $16 \%$ & $53,1 \%$ & $16 \%$ & $9,9 \%$ & $4,9 \%$ & $100 \%$ \\
\hline \multirow{4}{*}{$\begin{array}{c}\text { Identifikasi } \\
\text { Metode dan } \\
\text { Renovasi } \\
\text { Arsitektur } \\
\text { Organisasional }\end{array}$} & \multirow{2}{*}{7.} & 28 & 38 & 11 & 4 & 0 & 81 \\
\hline & & $34,6 \%$ & $40,9 \%$ & $13,6 \%$ & $4,9 \%$ & $0 \%$ & $100 \%$ \\
\hline & \multirow{2}{*}{8.} & 14 & 46 & 15 & 5 & 1 & 81 \\
\hline & & $17,3 \%$ & $56,8 \%$ & $18,5 \%$ & $6,2 \%$ & $1,2 \%$ & $100 \%$ \\
\hline Inisiatif dalam & 9. & 25 & 42 & 10 & 4 & 0 & 81 \\
\hline
\end{tabular}




\begin{tabular}{|c|c|c|c|c|c|c|c|}
\cline { 2 - 7 } \multirow{3}{*}{$\begin{array}{c}\text { Menyusun } \\
\text { Prioritas }\end{array}$} & $30,9 \%$ & $51,9 \%$ & $12,3 \%$ & $4,9 \%$ & $0 \%$ & $100 \%$ \\
\cline { 2 - 8 } & \multirow{2}{*}{10.} & 9 & 45 & 19 & 8 & 0 & 81 \\
\cline { 3 - 8 } & $11,1 \%$ & $55,6 \%$ & $23,5 \%$ & $9,9 \%$ & $0 \%$ & $100 \%$ \\
\hline
\end{tabular}

Sumber : Data Primer Hasil Penelitian, 2015 (data diolah)

Dari Tabel 3.1 diatas menunjukkan bahwa pada umumnya kualitas sepatu cibaduyut sudah sesuai dengan kebutuhan pelanggan ,32 $1 \%$ responden sangat setuju. Sedangkan pengrajin sepatu pada umumnya memahami perkembangan pasar dan bisnis persepatuan,29,6\% sangat seuju .Adapun tentang penghasilan profesi pengrajin juga pada umumnya sangat menjanjikan ,60,5\% responden setuju. Selain itu pengrajin memiliki visi jangka panjang tentang arah bisnis yang lebih baik ,sebesar 32,1\% responden setuju.selain itu pada umumnya pengrajin mengetahui kekuatan dan kelemahannya dalam berbisnis, 27,2 \% responden sangat setuju. Dan sebanyak $53,1 \%$ responden mengatakan setuju tentang pengrajin sepatu dapat menjalankan bisnisnya dengan efisien dan efektif.Selain itu para pengrajin umumnya sangat menguasai skill di bidangnya 34,6 \% respondensangat setuju . juga mayoritas pengrajin dapat menyesuaikan diri dengan baik daslam menyikapi perubahan dalam bisnis persepatuan, 30,9\% responden sangat setuju . Selain itu pengrajin juga dapat memahami strategi yang diterapkan dengan baik

Adapun Peran Human Capital sebagai Ahli Administrasi adalah dapat dilihat pada Tabel 3.2 sebagai berikut :

Tabel 3.2

Peran Human Capital Pengrajin Sebagai Ahli Administrasi

\begin{tabular}{|c|c|c|c|c|c|c|c|}
\hline Dimensi & No & SS(5) & $S(4)$ & $\mathbf{R R}(3)$ & TS(3) & STS(!) & Total \\
\hline \multirow{4}{*}{ Staffing } & \multirow{2}{*}{11} & 24 & 45 & 5 & 7 & 0 & 81 \\
\hline & & $29,6 \%$ & $55,6 \%$ & $6,2 \%$ & $8,6 \%$ & $0 \%$ & $100 \%$ \\
\hline & \multirow{2}{*}{12} & 15 & 49 & 13 & 4 & 0 & 81 \\
\hline & & $18,5 \%$ & $60,5 \%$ & $16 \%$ & $4,9 \%$ & $0 \%$ & $100 \%$ \\
\hline \multirow{2}{*}{ Rewarding } & \multirow{2}{*}{13} & 18 & 28 & 22 & 12 & 1 & 81 \\
\hline & & $22,2 \%$ & $34,6 \%$ & $27,2 \%$ & $14,8 \%$ & $1,2 \%$ & $100 \%$ \\
\hline \multirow{6}{*}{ Training } & \multirow{2}{*}{14} & 7 & 30 & 21 & 9 & 4 & 81 \\
\hline & & $8,6 \%$ & $37 \%$ & $25,9 \%$ & $23,5 \%$ & $4,9 \%$ & $100 \%$ \\
\hline & \multirow{2}{*}{15} & 9 & 22 & 25 & 21 & 4 & 81 \\
\hline & & $11,1 \%$ & $27,2 \%$ & $30,9 \%$ & $25,9 \%$ & $4,9 \%$ & $100 \%$ \\
\hline & \multirow{2}{*}{16} & 4 & 33 & 20 & 23 & 1 & 81 \\
\hline & & $4,9 \%$ & $40,7 \%$ & $24,7 \%$ & $28,4 \%$ & $1,2 \%$ & $100 \%$ \\
\hline \multirow{6}{*}{ Penilaian } & \multirow{2}{*}{17} & 9 & 37 & 17 & 17 & 1 & 81 \\
\hline & & $11,1 \%$ & $45,7 \%$ & $21 \%$ & $21 \%$ & $1,2 \%$ & $100 \%$ \\
\hline & \multirow{2}{*}{18} & 7 & 29 & 11 & 31 & 3 & 81 \\
\hline & & $8,6 \%$ & $35,8 \%$ & $13,6 \%$ & $38,3 \%$ & $3,7 \%$ & $100 \%$ \\
\hline & \multirow{2}{*}{19} & 4 & 32 & 7 & 36 & 2 & 81 \\
\hline & & $4,9 \%$ & $39,5 \%$ & $8,6 \%$ & $44,4 \%$ & $2,5 \%$ & $100 \%$ \\
\hline
\end{tabular}

Sumber : Data Primer Hasil Penelitian, 2015 (data diolah) 
Dari tabel 3.2 di atas, dapat dilihat bahwa pada umumnya pengrajin sepatu cibaduyut mampu menganalisa kebutuhan jumlah pengrajin,hal ini terliat bahwa $29.6 \%$ responden sangat setuju. Ini mengindikasikan bahwa parapengusaha sepatu di Cibaduyut dapat memenuhi kebutuhan sumber daya manusianya, terutama pada pemenuhan kebutuhan tenaga pengrajin sepatu di Cibaduyut. Selain itu pada umumnya pengusaha sepatu cibaduyut, mampu merancang dan mengembangkan kemampuan pengrajin sepatu dengan efisien. Bahwa 18,5\% responden sangat setuju, selanjutnya sebesar $60,5 \%$ responden setuju, $16 \%$ responden ragu-ragu, tidak setuju 4,9\% dan terakhir $0 \%$ sangat tidak setuju. Ini mengindikasikan bahwa para pengrajin sepatu Cibaduyut dapat bekerja sesuai rancangan para pengusaha, dapat mengembangkan kemampuannya dan sudah bekerja secara efisien . Dan pada umumnya pengusaha sepatu cibaduyut memberikan promosi/ kenaikan pangkat (kenaikan gaji dll) kepada pengrajin sepatu yang berprestrasi.Itu terliat bahwa sebesar $45,7 \%$ responden setuju. Selain itu juga pada umumnya pengusaha sepatu cibaduyut memberikan demosi/ penurunan pangkat (pengurangan gaji dll) kepada pengrajin sepatu yang berkinerja buruk. Itu terliat bahwa, sebesar 39,5\% responden setuju.

Berikut peran Human Capital Pengrajin sebagai Infrastruktur ,akan terlihat dalam Tabel 3.3 sebagai berikut :

Tabel 3.3

Peran Human Capital Pengrajin Sebagai Infrastruktur

\begin{tabular}{|c|c|c|c|c|c|c|c|}
\hline Dimensi & No & SS(5) & S(4) & $\mathbf{R R}(3)$ & TS(3) & STS(!) & Total \\
\hline \multirow{6}{*}{$\begin{array}{c}\text { Proses } \\
\text { Operasional }\end{array}$} & \multirow{2}{*}{20} & 18 & 43 & 14 & 6 & 0 & 81 \\
\hline & & $22,2 \%$ & $53,1 \%$ & $17,3 \%$ & $7,4 \%$ & $0 \%$ & $100 \%$ \\
\hline & \multirow{2}{*}{21} & 8 & 21 & 16 & 33 & 3 & 81 \\
\hline & & $9,9 \%$ & $25,9 \%$ & $19,8 \%$ & $40,7 \%$ & $3,7 \%$ & $100 \%$ \\
\hline & \multirow{2}{*}{22} & 18 & 43 & 12 & 8 & 0 & 81 \\
\hline & & $22,2 \%$ & $53,1 \%$ & $14,8 \%$ & $9,9 \%$ & $0 \%$ & $100 \%$ \\
\hline \multirow{4}{*}{ Komitmen } & \multirow{2}{*}{23} & 31 & 36 & 9 & 5 & 0 & 81 \\
\hline & & $38,3 \%$ & $44,4 \%$ & $11,1 \%$ & $5,2 \%$ & $0 \%$ & $100 \%$ \\
\hline & \multirow{2}{*}{24} & 18 & 48 & 12 & 3 & 0 & 81 \\
\hline & & $22,2 \%$ & $59,3 \%$ & $14,8 \%$ & $3,7 \%$ & $0 \%$ & $100 \%$ \\
\hline \multirow{6}{*}{ Kontribusi } & \multirow{2}{*}{25} & 8 & 29 & 20 & 21 & 3 & 81 \\
\hline & & $9,9 \%$ & $35,8 \%$ & $24,7 \%$ & $25,9 \%$ & $3,7 \%$ & $100 \%$ \\
\hline & \multirow{2}{*}{26} & 23 & 34 & 15 & 9 & 0 & 81 \\
\hline & & $28,4 \%$ & $42 \%$ & $18,5 \%$ & $11,1 \%$ & $0 \%$ & $100 \%$ \\
\hline & \multirow{2}{*}{27} & 17 & 36 & 19 & 9 & 0 & 81 \\
\hline & & $21 \%$ & $44,4 \%$ & $23,5 \%$ & $11,1 \%$ & $0 \%$ & $100 \%$ \\
\hline \multirow{4}{*}{ Loyalitas } & \multirow[b]{2}{*}{28} & 17 & 36 & 19 & 9 & 0 & 81 \\
\hline & & $21 \%$ & $44,4 \%$ & $23,5 \%$ & $11,1 \%$ & $0 \%$ & $100 \%$ \\
\hline & \multirow[t]{2}{*}{29} & 21 & 48 & 10 & 2 & 0 & 81 \\
\hline & & $25,9 \%$ & $59,3 \%$ & $12,5 \%$ & $2,5 \%$ & $0 \%$ & $100 \%$ \\
\hline \multirow{2}{*}{$\begin{array}{c}\text { Kemampuan } \\
\text { SDM / Kinerja }\end{array}$} & \multirow{2}{*}{30} & 25 & 49 & 5 & 2 & 0 & 81 \\
\hline & & $30,9 \%$ & $60,5 \%$ & $6,2 \%$ & $2,5 \%$ & $0 \%$ & $100 \%$ \\
\hline
\end{tabular}




\begin{tabular}{|c|r|r|r|r|r|r|}
\hline \multirow{2}{*}{31} & 24 & 49 & 5 & 3 & 0 & 81 \\
\cline { 2 - 7 } & $29,6 \%$ & $60,5 \%$ & $6,2 \%$ & $3,7 \%$ & $0 \%$ & $100 \%$ \\
\hline \multirow{2}{*}{32} & 24 & 41 & 11 & 5 & 0 & 81 \\
\cline { 2 - 7 } & $29,6 \%$ & $50,6 \%$ & $13,6 \%$ & $6,2 \%$ & $0 \%$ & $100 \%$ \\
\hline & & & & & & \\
\hline
\end{tabular}

Dari tabel 3.3 di atas, menunjukkan bahwa sebesar 53,1\% responden setuju, mayoritas proses operasional pembuatan sepatu oleh para pengrajin sepatu di Cibaduyut sudah bekerja dengan efisien, hal ini membuat pihak pengusaha sepatu untung dalam efisiensi proses operasional pembuatan sepatu. Sedangkan pengrajin yang melakukan pembuatan sepatu dengan menggunakan teknologi terbaru ,sebanyak 25,9 \% setuju,tetapi sebanyak 40,7\% tidak setujuk setuju. Ini mengindikasikan bahwa teknologi belum menyentuh sebagian besar para pengrajin sepatu Cibaduyut dalam proses operasional pembuatan sepatu, sebagian besar masih menggunakan alat tradisional. Selain itu bahwa sebanyak 53,1 \% mengatakan setuju bahwa produktifitas pengrajin sepatu sudah baik.Begitu juga sebesar 44,4 \% setuju tentang pengrajin yang bersungguh-sungguh dalam bekerja, serta memiliki komitmen yang tinggi dalam menjalankan profesinya .Dan pada umumnya pengrajin sepatu cibaduyut memiliki tinggat pendidikan yang baik dalam menjalankan profesinya, sebesar 35,8\% responden setuju. Disamping itu sebanyak $42 \%$ setuju bahwa ,paada umumnya pengrajin sepatu cibaduyut dapat memberikan saran kepada pengusaha sepatu cibaduyut dalam proses pembuatan sepatu demi perbaikan terus menerus. Selain itu sebanyak 44,4 \% setuju bahwa pada umumnya pengrajin sepatu cibaduyut memiliki loyalitas yang tinggi pada satu pengusaha sepatu. Dan pada umumnya pengrajin sepatu cibaduyut memiliki kinerja yang baik, sebesar 59,3\% responden setuju. Selain itu pada umumnya pengrajin sepatu cibaduyut memiliki keahlian yang baik dalam pembuatan sepatu, bahwa sebesar $60,5 \%$ responden setuju.Serta mayoritas pengrajin sepatu di Cibaduyut memiliki kapabilitas dan kemampuan dalam pembuatan sepatu,sebanyak 60,5\% setuju. Serta pada umumnya pengrajin sepatu cibaduyut memiliki kecepatan yang baik dalam pembuatan sepatu, sebesar $50,6 \%$ responden setuju,

Tabel .3.4

Peran Human Capital Pengrajin Sebagai Agen Perubahan

\begin{tabular}{|c|c|c|c|c|c|c|c|}
\hline Dimensi & No & SS(5) & $S(4)$ & RR(3) & TS(3) & STS(!) & Total \\
\hline \multirow{2}{*}{$\begin{array}{c}\text { Menangkap } \\
\text { Perubahan }\end{array}$} & \multirow{2}{*}{33} & 18 & 50 & 10 & 3 & 0 & 81 \\
\hline & & $22,2 \%$ & $61,7 \%$ & $12,3 \%$ & $3,7 \%$ & $0 \%$ & $100 \%$ \\
\hline \multirow{4}{*}{$\begin{array}{l}\text { Mengkapitalisasi } \\
\text { Perubahan }\end{array}$} & \multirow{2}{*}{34} & 19 & 44 & 13 & 5 & 0 & 81 \\
\hline & & $23,5 \%$ & $54,3 \%$ & $16 \%$ & $6,2 \%$ & $0 \%$ & $100 \%$ \\
\hline & \multirow{2}{*}{35} & 25 & 43 & 6 & 7 & 0 & 81 \\
\hline & & $30,9 \%$ & $53,1 \%$ & $7,4 \%$ & $8,6 \%$ & $0 \%$ & $100 \%$ \\
\hline \multirow{6}{*}{ Inisiatif Perubahan } & \multirow{2}{*}{36} & 7 & 44 & 10 & 19 & 1 & 81 \\
\hline & & $8,6 \%$ & $54,3 \%$ & $12,3 \%$ & $23,5 \%$ & $1,2 \%$ & $100 \%$ \\
\hline & \multirow{2}{*}{37} & 28 & 44 & 6 & 3 & 0 & 81 \\
\hline & & $34,6 \%$ & $54,3 \%$ & $7,4 \%$ & $3,7 \%$ & 0 & $100 \%$ \\
\hline & \multirow{2}{*}{38} & 19 & 48 & 10 & 4 & 0 & 81 \\
\hline & & $23,5 \%$ & $59,3 \%$ & $12,3 \%$ & $4,9 \%$ & 0 & $100 \%$ \\
\hline Strategi SDM & 39 & 28 & 46 & 5 & 2 & 0 & 81 \\
\hline
\end{tabular}




\begin{tabular}{|l|r|r|r|r|r|r|r|}
\cline { 2 - 8 } Masa Depan & $34,6 \%$ & $56,8 \%$ & $6,2 \%$ & $2,5 \%$ & $0 \%$ & $100 \%$ \\
\cline { 2 - 8 } & \multirow{3}{*}{40} & 21 & 50 & 9 & 1 & 0 & 81 \\
\cline { 2 - 8 } & $25,9 \%$ & $61,7 \%$ & $11,1 \%$ & $1,2 \%$ & $0 \%$ & $100 \%$ \\
\cline { 2 - 8 } & \multirow{2}{*}{41} & 22 & 49 & 7 & 3 & 0 & 81 \\
\cline { 2 - 8 } & $27,2 \%$ & $60,5 \%$ & $8,6 \%$ & $3,7 \%$ & $0 \%$ & $100 \%$ \\
\cline { 2 - 8 } & \multirow{2}{*}{42} & 25 & 42 & 12 & 2 & 0 & 81 \\
\cline { 3 - 8 } & & $30,9 \%$ & $51,9 \%$ & $14,8 \%$ & $2,5 \%$ & $0 \%$ & $100 \%$ \\
\hline
\end{tabular}

Dari table 3.4 di atas, dapat dilihat bahwa sebesar $61,7 \%$ responden setuju, para pengrajin sepatu di Cibaduyut dapat dengan leluasa menyampaikan pendapatnya dan ide dalam proses pembuatan sepatu.Selanjutnya sebesar $54,3 \%$ responden setuju, bahwa tingkat kerjasama di antara para pengrajin sepatu di Cibaduyut sangat baik dan tidak ada masalah, para pengrajin pun dapat menciptakan suasana usaha yang kondusif dalam bekerja dan solid dalam tim. Selain itu sebesar 53,1\% responden setuju, bahwa para pengrajin sepatu di Cibaduyut sangat fleksibel dalam menghadapi perubahan lingkungan bisnis persepatuan dan dapat mengikuti dengan baik perubahan itu. Dan sebesar 54,3\% responden setuju bahwa para pengrajin sepatu di Cibaduyut sangat cakap dalam memanfaatkan teknologi dan strategi dari perubahan lingkungan bisnis sepatu. Sedangkan sebesar $54,3 \%$ responden setuju, bahwa pengrajin sepatu Cibaduyut memiliki pemahaman tugas dan pekerjaannya dengan baik.Berikutnya sebesar 59,3\% responden setuju, bahwa budaya kerja di antara para pengrajin sepatu di Cibaduyut sangat kondusif dan baik.

Adapun untuk memahami gambaran human capital pengrajin secara keseluruhan dapat terlihat pada Tabel 3.5 berikut :

Tabel 3.5

Human Capital Para Pengrajin Sepatu di Cibaduyut

\begin{tabular}{|c|c|c|c|}
\hline SKOR & FREKUENSI & PRESENTASE & $\begin{array}{c}\text { SKOR } \\
\text { KUMULATIF }\end{array}$ \\
\hline 1 & 35 & $1,02 \%$ & 35 \\
\hline 2 & 392 & $11,52 \%$ & 784 \\
\hline 3 & 507 & $14,9 \%$ & 1521 \\
\hline 4 & 1714 & $50,39 \%$ & 6856 \\
\hline 5 & 754 & $22,17 \%$ & 3770 \\
\hline TOTAL & $\mathbf{3 4 0 2}$ & $\mathbf{1 0 0 , 0 \%}$ & $\mathbf{1 2 9 6 6}$ \\
\hline
\end{tabular}

Sumber : Data Primer Hasil Penelitian, 2015 (data diolah) 


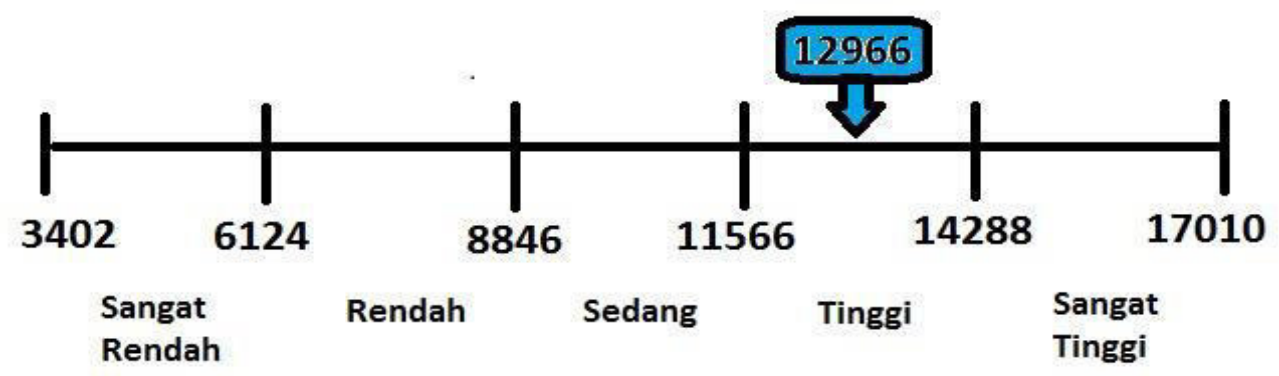

Gambar 3.1

\section{Interval Variabel Human Capital Pengrajin sepatu di Cibaduyut}

Berdasarkan gambar 3.1 yang berisi interval variabel human capital pengrajin sepatu di Cibaduyut, total skor kumulatif organisasi pembelajaran pada pada para pengrajin sepatu di Cibaduyut adalah 12966 dan tergolong dalam interval tinggi, sehingga dapat disimpulkan bahwa secara human capital pengrajin sepatu di Cibaduyut adalah tinggi.Artinya bahwa para pengrajin sepatu memiliki kemampuan untuk berdaya saing dalam meningkatkan wisman Jawa Barat.

\subsection{Analisis Verifikatif}

Pada penelitian ini ingin menganalisis dimensi-dimensi peran Human Capital pada Pengrajin sepatu dikawasan wisata belanja sepatu Cibaduyut. Dengan analisis faktor, akan didapatkan berapa jumlah faktor yang terbentuk dan pengelompokan dimensi-dimensi pada faktor yang tepat. Pengelompokan pada faktor yang tepat akan mempermudah analisis selanjutnya yaitu pemetaan dimensi-dimensi yang membentuk peran Human Capital Pengrajin sepatu.Proses untuk analisis faktor ini digunakan bantuan software SPSS 22.0for Windows.

\subsubsection{Uji Asumsi Analisis Faktor}

1. Korelasi antar variabel Independen. Besar korelasi atau korelasi antar independen variabel harus cukup kuat, misalnya di atas 0,5.

2. Korelasi Parsial. Besar korelasi parsial, korelasi antar dua variabel dengan menganggap tetap variabel yang lain, justru harus kecil. Pada SPSS deteksi terhadap korelasi parsial diberikan lewat pilihan Anti-Image Correlation.

3. Pengujian seluruh matriks korelasi (korelasi antar variabel), yang diukur dengan besaran Bartlett Test of Sphericity atau Measure Sampling Adequacy (MSA). Pengujian ini mengharuskan adanya korelasi yang signifikan di antara paling sedikit beberapa variabel. 


\subsubsection{Uji Asumsi Analisis Faktor Korelasi antar variabel Independen}

Pengujian asumsi 1 korelasi anta Varibel Independen, seperti pada tabel 3.6 dibawah ini,

Tabel 3.6

KMO and Bartlett's Test

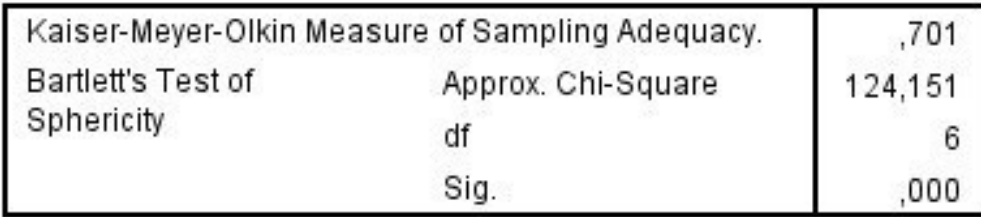

Sumber : Data kuesioner yang telah diolah, 2015

Kaiser Meyer Olkin Measure of Sampling (KMO) adalah indek perbandingan jarak antara koefisien korelasi dengan koefisien korelasi parsialnya. Jika jumlah kuadrat koefisen korelasi parsial di antara seluruh pasangan variabel bernilai kecil jika dibandingkan dengan jumlah kuadrat koefisien korelasi, maka akan menghasilkan nilai KMO mendekati 1. Nilai KMO dianggap mencukupi jika lebih dari 0,5. Hasil dari tabel 1 penelitian menunjukkan bahwa nilai Kaiser Meyer Olkin Measure of Sampling sebesar 0,701. Dengan demikian persyaratan KMO memenuhi persyaratan karena memiliki nilai di atas 0,5.

Pada uji asumsi faktor korelasi pasial, dapat dilihat pada tabel5 dibawah ini dengan melihat output Measures of Sampling Adequacy (MSA). Pengujian persyaratan MSA terhadap 4 variabel, dijelaskan pada tabel di bawah ini :

Tabel 3.6

Anti-image Matrices

\begin{tabular}{|ll|r|r|r|r|}
\hline & & Mitra Strategik & $\begin{array}{c}\text { Ahli } \\
\text { Administratif }\end{array}$ & Infrastruktur & $\begin{array}{c}\text { Agen } \\
\text { Perubahan }\end{array}$ \\
\hline Anti-image Covariance & Mitra Strategik &, 432 &,- 014 &,- 101 &,- 221 \\
& Ahli Administratif &,- 014 &,, 849 &,- 216 &, 073 \\
& Infrastruktur &,- 101 &,- 216 &, 455 &,- 175 \\
& Agen Perubahan &,- 221 &, 073 &,- 175 &, 380 \\
\hline Anti-image Correlation & Mitra Strategik &, $731^{\text {a }}$ &,- 023 &,- 228 &,- 546 \\
& Ahli Administratif &,- 023 &, $580^{\text {a }}$ &,- 347 &, 129 \\
& Infrastruktur &,- 228 &,- 347 &, $734^{\text {a }}$ &.,- 420 \\
& Agen Perubahan &,- 546 &, 129 &,- 420 &, $672^{\text {a }}$ \\
\hline
\end{tabular}

a. Measures of Sampling Adequacy(MSA)

Sumber : Data kuesioner yang telah diolah, 2015

Dapat dilihat pada table 3.6 nilai MSA pada tabel di atas ditunjukkan pada baris Anti Image Correlation dengan tanda "a". Misal "Mitra Strategik" nilai MSA = 0,731, "Ahli Administratif" nilai MSA $=0,580$, "Infrastruktur" nilai MSA $=0,734$, dan terakhir "Agen Perubahan"nilai MSA $=0,672$. Ini berarti semua dimensi memenuhi persyaratan dikarenakan nilai MSA >0,5 


\subsubsection{Uji Asumsi Analisis FaktorPengujian Seluruh Matriks Korelasi}

Pada uji asumsi analis faktor pengujian seluruh matriks korelasi Pengujian, dapat dilihat pada table 3.7 , dibawah ini

Tabel 3.7

\section{Communalities}

\begin{tabular}{l|c|r|}
\hline & \multicolumn{1}{|c|}{ Initial } & Extraction \\
\hline Mitra Strategik & 1,000 &, 748 \\
Ahli Administratif & 1,000 &, 175 \\
Infrastruktur & 1,000 &, 764 \\
Agen Perubahan & 1,000 &, 772 \\
\hline
\end{tabular}

Sumber : Data kuesioner yang telah diolah, 2015

Dari table 3.7, diatas semua dimensi yang di uji dilihat dari kolom extraction $>0,5$ ini berarti terdapat 3 dimensi yang memenuhi persyaratan communalities, yaitu:Mitra Strategik, Infrastruktur, Agen Perubahan.Sedangkan dimensi Ahli Administratif berada di bawah angka 0,5 yang berarti tidak memenuhi persyaratan. Setelah melalui persyaratanketiga asumsi tersebut berarti data yang ada memenuhi prasyarat untuk dianalisis lebih lanjut, dengan menggunakan analisis faktor.

Pada table 3.7 dapat dilihat menunjukkan seberapa besar sebuah dimensi dapat menjelaskan faktor. Seperti "Mitra Strategik" sebesar 0,748, artinya dimensi ini dapat menjelaskan faktor sebesar 74,8\%. Dimensi "Ahli Administratif"sebesar 0,175, artinya dimensi ini menjelaskan faktor sebesar 17,5\%. Dimensi "Infrastruktur"sebesar 0,764, artinya dimensi ini menjelaskan faktor sebesar 76,4\%, dan terakhir dimensi "Agen Perubahan" sebesar 0,772, artinya variabel ini menjelaskan faktor sebesar 77,2\%. Dari keempatdimensi tersebut dimensi "Agen Perubahan" yang paling tinggi yaitu sebesar 77,2\%,yang menjelaskan factor peran Human Capital sebagai agen perubahan. Dengan di temukan faktor terbesar peran Human Capital ini salah satu upaya menghadapi persaingan yang semakin ketat di tingkat global , pengrajin dituntut untuk memiliki daya adaptasi dan daya tahan serta kemampuan melakukan perubahan arah yang cepat yang terfokus pada pengembangan wisata dilihat dari sisi pengrajin agar meningkatkan ketertarikan turis melakukan kunjungan wisata.

\subsubsection{Penentuan Banyak Faktor}

Penentuan banyak faktor dapat dilihat pada tabel 3.8. Total Variance Explained di bawah ini berguna untuk menentukan berapakah faktor yang mungkin dapat dibentuk. 


\section{Tabel 3.8}

Total Variance Explained

\begin{tabular}{|l|r|r|r|r|r|r|}
\hline \multirow{2}{*}{ Component } & \multicolumn{3}{|c|}{ Initial Eigenvalues } & \multicolumn{3}{|c|}{ Extraction Sums of Squared Loadings } \\
\cline { 2 - 7 } & \multicolumn{1}{|c|}{ Total } & \% of Variance & Cumulative \% & \multicolumn{1}{c|}{ Total } & \% of Variance & Cumulative \% \\
\hline 1 & 2,459 & 61,472 & 61,472 & 2,459 & 61,472 & 61,472 \\
2 &, 940 & 23,498 & 84,970 & & & \\
3 &, 351 & 8,784 & 93,754 & & & \\
4 &, 250 & 6,246 & 100,000 & & & \\
\hline
\end{tabular}

Extraction Method: Principal Component Analysis.

Sumber : Data kuesioner yang telah diolah, 2015

Berdasarkan table 3.8 di atas, lihat kolom "Component" yang menunjukkan bahwa ada 4dimensi yang dapat mewakili variabel. Perhatikan kolom "Initial Eigenvalues" yang dengan SPSS 22.0 kita tentukan nilainya 1 (satu). Varians bisa diterangkan oleh dimensi 1 adalah $2.459 / 4 \times 100 \%=61,475 \%$. Dengan demikian, karena nilai Eigenvalues yang ditetapkan 1, maka nilai Total yang akan diambil adalah yang $>1$ yaitu component 1 . Faktor yang paling dominan membentuk Human Capital yaitu sebesar 61,472\%, ini tergolong cukup tinggi. Agar dapat menjawab tantangan meningkatkan kunjungan wisata dengan mendongkrak kulitas Human Capital.

\subsubsection{Factor Loading}

Setelah kita mengetahui bahwa faktor maksimal yang bisa terbentuk adalah 1 faktor, selanjutnya kita melakukan penentuan masing-masing dimensi pada fatkor tersebut. Cara menentukan tersebut adalah dengan melihat tabel 3.9 Component Matrix seperti di bawah ini:

Tabel 3.9

\section{Component Matrix ${ }^{a}$}

\begin{tabular}{|l|r|}
\hline & Component \\
\cline { 2 - 2 } & \multicolumn{1}{|c|}{1} \\
\hline Mitra Strategik &, 865 \\
Ahli Administratif &, 418 \\
Infrastruktur &, 874 \\
Agen Perubahan &, 878 \\
\hline
\end{tabular}

Extraction Method: Principal

Component Analysis.

a. 1 components extracted.

Sumber : Data kuesioner yang telah diolah, 2015

Tabel 3.9. Di atas menunjukkan seberapa besar sebuah variabel berkorelasi dengan faktor yang akan dibentuk. Pada dimensi "Mitra Strategik" berkorelasi sebesar 0,865. : Dimensi "Ahli 
Administratif" berkorelasi sebesar 0,418. : Dimensi "Infrastruktur" berkorelasi sebesar 0,874. Sedangkan Dimensi “Agen Perubahan” berkorelasi sebesar 0,878

\section{Simpulan dan Saran}

\subsection{Simpulan}

Berdasarkan pemaparan diatas dapat disimpulakan sebagai berikut :

Peran human capital,terdiri dari empat dimensi yaitu Mitra Strategik, Ahli Administratif, Infrastruktur dan Agen Perubahan. Berdasarkan analisis deskriptif peran human capital pengrajin sepatu cibaduyut secara keseluruhan pada posisi intenterval yang tinggi, ini dapat menjadi modal meningkatkan daya saing untuk meningkatkan wisman khususnya wisman Jawa Barat. Dari uji verifikatif mendapatkan temuan bahwa yang paling besar menjelaskan faktor adalah "Agen Perubahan" yaitu sebesar 77,2\%, sedangkan dimensi yang paling kecil menjelaskan faktor adalah "Ahli Administrasi "sebesar 17,5\%.

Dimensi "Agen Perubahan" terdiri dari empat indikator yaitu menangkap perubahan, mengkapitalisasi perubahan, inisiatif perubahan dan strategi sdm masa depan. Dari hasil analisis deskriptif, ada dua indikator yang paling berperan pertama adalah Inisiatif Perubahan Ini mengindikasikan bahwa pengrajin sepatu Cibaduyut memiliki pemahaman tugas dan pekerjaannya dengan baik. Yang paling berperan kedua adalah strategi SDM masa depan yaitu "Pada umumnya pengrajin sepatu cibaduyut memiliki keinginan dan upaya dalam peningkatan produktivitas"

Dimensi Ahli Admistratif terdiri dari empat indikator yaitu staffing, rewarding, training, dan penilaian. Dari hasil analisis deskriptif, ada dua indikator yang paling kecil pertama indikator training, mengindikasikan bahwa pada umumnya pengrajin sepatu di Cibaduyut belum mendapatkan pendidikan dan pelatihan. Yang kedua indikator penilaian, mengindikasikan bahwa pada umumnya pengrajin sepatu Cibaduyut tidak mendapatkan demosi/penurunan pangkat (pengurangan gaji dll) kepada pengrajin sepatu yang berkinerja buruk, dan sebagian lagi mendapatkan demosi.

\subsection{Saran}

Berdasarkan simpulan penelitian, peneliti memberikan saran, agar peran human capital pengrajin sepatu Cibaduyut dapat meningkatkan kunjungan wisman mancanegara sebagai berikut :

1. Dimensi mitra strategik dalam peran human capital yang sudah baik seperti inisiatif perubahan dan strategi SDM masa depan agar terus dijaga dan terus di tingkatkan dengan

a. Saat ini pengrajin sepatu Cibaduyut pada umumnya memiliki pemahaman tugas dan pekerjaannya dengan baik, ini walaupun sudah baik perlu terus di tingkatkan dengan cara memberikan informasi update perkembangan teknik pembuatan sepatu, pemasaran dan hal lain yang terkait dengan industry atau bisnis persepatuan. 
b. Saat ini pengrajin sepatu Cibaduyut pada umumnya memiliki keinginan dan upaya dalam meningkatkan produktivitas sudah baik, ini walaupun sudah baik harus diimbangi terserapnya produksi sepatu hasil pengarajin sepatu Cibaduyut dapat terus diterima pasar.

2. Dimensi ahli administratif yang kurang baik seperti training dan penilaian

a. Saat ini pengusaha pengrajin sepatu Cibaduyut pada umumnya kurang kurang memberikan perhatian lebih dengan memberikan pendidikan dan pelatihan untuk pengrajin sepatu, oleh karena itu peneliti mensarankan para pengusaha agar memberikan perhatian lebih dalam pemberikan pelatihan persepatuan khsususnya pelatihan tekniknik pembuatan sepatu yang berkuliatas, teknik pengemasan dan tekik pemasaran yang baik agar ini dikemudian hari tidak lagi menjadi titik lemah. Dan diharpkan stockholeder mampu memberikan kontribusi atau pelatihan lebih terhadap pelatian pengrajin sepatu Cibaduyut.

b. Saat ini pada umunya pengusaha sepatu cibaduyut tidak memberikan demosi/ penurunan pangkat (pengurangan gaji dll) kepada pengrajin sepatu yang berkinerja buruk, kepada pengrajin sepatu yang berkinerja dibawah standar, peneliti mensarankan agar menjadikan perhatian lebih sehingga yang berkinerja diwah strandar diberikan demosi demosi/ penurunan pangkat (pengurangan gaji dll) agar jelas penghargaan dan hukumanya, sehingga dapat meningkatkan kinerja dan lebih bersifat objektif terkait dengan penilaian kinerja pengrajin sepatu Cibaduyut.

\section{Daftar Pustaka}

Anissa Ciptagustia. 2014. Pengaruh Manajemen Bakat Terhadap Pembentukan Kemampuan Khas Serta Implikasinya Pada Keunggulan Bersaing (Survei Pada PerusahaanFurniture Rotan Anggota ASMINDO Cirebon). Tesis Unpad Bandung.

Amstrong, Michael. 2006. A Handbook of Human Resources Management Practice. $10^{\text {th }}$ Edition. Kogan Page. London and Philadelphia. p.391.

Baron, A., \& Armstrong, M. 2007. Human Capital Management: Achieving added value through people. London: Kogan page.

Barney, J.B dan Delwyn N. Clark. 2007. Resourced Based Theory"Creating and SustainingCompetitive Advantage”. Oxford University Press. UK. p. 52.

Carmeli, Abraham. 2004. Asseing Core Intangible Resources. European Management Journal Vol.22, No.1, p.121.

Djurica, Maja, Nina, Maja and Janicic, Radmila. 2014.Building Competitive AdvantageThrough Human Capital.The Clute Institute International Academic Conference. Munich, Germany 2014. 
Emily Auw. 2009. Human Capital, Capabilities \& Competitive Advantage.International Review of Business Research Papers Vol. 5 No. 5 September 2009 Pp. 25-36.

Firer, S. \& Mitchell, S.W. 2003. Intellectual capital and traditional measures ofcorporate performance', Journal of Intellectual Capital. vol. 4(3), pp. 348-60

Galbreath. Jeremy Thomas. 2004. Determinants of Firm Success: A Resources-Based Analysis. Thesis. Curtin Universitu of Technology. p.61.

Ghea Utariani S dan Reza Anshari N. 2013.Barriers in Adopting Original Brand Manufacturing Practice among Indonesia's Footwear SME. Proceedings of 4th Asia-Pacific Business Research Conference 30 September - 1 October 2013, Bay view Hotel, Singapore, ISBN: 978-1-922069-31-3.

Istijanto. 2006. Riset Sumber Daya Manusia. Jakarta : PT Gramedia Pustaka Utama.

Joeliaty. 2012.Pengaruh Modal Intelektual Dan Manajemen Pengetahuan Terhadap Keunggulan Bersaing Dan Dampaknya Terhadap Kinerja Program Studi( Suatu Kajian Pada Perguruan Tinggi Negeri Di Bandung). Desertasi Unpad Bandung.

Joeliaty. 2014. Analisis Faktor Kompetensi Pengrajin Sebagai Daya SaingDalam Menghadapi Masyarakat Ekonomi Asean (MEA)" (Kajian Pada Sentra Sepatu Cibaduyut). Konfrensi Forum Manajemen Indonesia ke 6 Medan.

Millmore. Mike, Philip Lewis, Mark Saunders, Adrian Thornhill, Trevor Morrow. 2007. Strategic Human Resources Management "Contemporary Issues". Pearson education Limited. England. P.6.

Mudrajat Kuncoro. 2003. Metode Riset Untuk Bisnis dan Ekonomi. Jakarta : Erlangga.

Nazir. 2005. Metode penelitian. Bogor : Ghalia Indonesia.

Newber, Scot L. 2007. Empirical Research on The Resources Based View of The Firm: An Assessment And Suggestions For Future Research. Strategic Management Journal, 28. P. 123.

Peteraf, M.A. \& Barney, J.B. 2003. "Unravelling the resource-based tangle',Managerial and Decision Economics”, vol. 24, pp. 309-323

Ratna Kusumawati. 2010. Pengaruh Karakteristik Pimpinan Dan Inovasi Produk Baru Terhadap Kinerja Perusahaan Untuk Mencapai Keunggulan Bersaing Berkelanjutan. AKSES: Jurnal Ekonomi dan Bisnis. Vol. 545 No. 9, April 2010. P.56-58.

Raymond A.Noe, Jhon R. Hollenbek, Barry Gerhart, Patrick M.Wright. 2010. Manajemen Sumber Daya Manusia "Mencapai Keunggulan Bersaing”. Buku 1. Salemba Empat. P. 45. 
Siddiqui, Faryal. 2012. Human Capital Management: An EmergingHuman Resource Management Practice. International Journal of Learning \& DevelopmentISSN 216440632012, Vol. 2, No. 1

Tantie Koestantia, Wiendu Nuryanti, Nindyo Suwarno, Budi Prayitno dan Devi Femina. 2014. The Distribution Pattern of Creative Industries and the Spatial System of Tourist Destinations in Indonesia: The Case of Bandung. International Journal of Architecture and Design, ISSN:2051-5820, Vol.25, Issue.2.

Tontowi Jauhari. 2012 “Perspektif human capital Sebagai pilihan perubahan”. Jurnal Bina alUmmah, Volume VII, Nomor 1, Januari 2012.

Yan Megawandi. 2013. Koordinasi Antar Organisasi Dalam Pembangunan Pariwisata Di Provinsi Kepulauan Bangka Belitung. Desertasi. Unpad Bandung.

Yulia Widarti. 2015. Local Government Attitudes toward Sustainable TourismDevelopment (Case of Bandung City, Indonesia).Manuscript received December 27, 2014; revised March 12, 2015 International Journal of Social Science and Humanity, Vol. 6, No. 7, July 2016

Joeliaty, Hilmiana, Adhi Prapaskah Hartadi dan Erman Sumirat. 2014. Kualifikasi Human Capital Dalam Rangka Mengembangkan Kesempatan Kerja Masyarakatlokal Di Proyek Geohermal Cibuni Jawa Barat. Laporan Penelitian Unggulan Perguruan Tinggi. Unpad Bandung

Laporan Dinas Kebudayaan dan pariwisata Kota Bandung 2015.

Laporan Kementrian Pariwisata Wisman Mancanegara 2015.

Undang-undang Nomor 10 tahun 2009 Tentang Kepariwisataan

Badan Pusat Statistik Tahun 2015.

Badan Pusat Statistik Kota Bandung 2015 .

http://www.pikiran-rakyat.com/ PR Online 7 Maret 2012, diakses 30 Mei 2015

http://www.tabloidbintang.com/diakses tanggal 28 Mei 2015 